\title{
Sensorineural Hearing Loss and Neural Correlates of Temporal Acuity in the Inferior Colliculus of the C57bl/6 Mouse
}

\author{
Joseph P. Walton ${ }^{1,2}$, Kathy Barsz ${ }^{1}$, and Willard W. Wilson ${ }^{1}$ \\ ${ }^{1}$ Otolaryngology Division of Department of Surgery, University of Rochester School of Medicine $\mathcal{E}$ Dentistry, Box-629 Rochester, \\ NY 14642, USA \\ ${ }^{2}$ Department of Neurobiology and Anatomy, University of Rochester School of Medicine E Dentistry, Rochester, NY 14642, \\ USA
}

Received: 2 May 2007; Accepted: 25 September 2007; Online publication: 10 November 2007

\begin{abstract}
Perception of complex sounds depends on the encoding of the dynamic and static structures within the ongoing stimulus by the auditory system. Aging has been associated with deficits in both areas, thus, the difficulty that the elderly have in speech comprehension could due to hearing loss, or to a loss of temporal sensitivity, or some combination of both. We investigated the effects of sensorineural hearing loss (SNHL) on neural correlates of temporal resolution by recording the responses of inferior colliculus neurons to a gap detection paradigm. We used C57BL/6 (C57) strain of laboratory mouse, which carries the $A h l$ deafness gene that initiates a progressive high frequency SNHL beginning at about 2 months of age and rapidly progresses to total deafness by 18 months. We compared gap encoding from inferior collicular neurons from young, normal-hearing C57 mice and middle-aged, hearing-impaired, C57 mice, quantifying minimal gap threshold, and recovery functions. The proportion of unit types, spontaneous rates and degree of monotonicity were comparable between young and middle-aged C57 mice. As expected, single unit thresholds were elevated by $30-40 \mathrm{~dB}$ in middleaged C57 mice. However, no significant differences in mean minimal gap thresholds or in the slopes of the gap recovery functions were found between the two age groups. Thus, the results suggest that moderate
\end{abstract}

Correspondence to: Joseph P. Walton - Otolaryngology Division of Department of Surgery - University of Rochester School of Medicine \& Dentistry · Box-629 Rochester, NY 14642, USA. Telephone: +1-716-2751248; fax: +1-716-2444103; email: joseph_ walton@urmc.rochester.edu high frequency SNHL does not affect temporal processing as measured by the gap detection paradigm.

Keywords: presbycusis, gap detection, inferior colliculus, hearing loss, mouse

\section{INTRODUCTION}

The gap-detection paradigm has been utilized as a measure of behavioral and neural temporal acuity in the auditory system (Allen et al. 2003; Barsz et al. 2000; Ison and Allen 2003; Walton et al. 1998). Several studies have found that minimum gap thresholds (MGTs) of hearing-impaired listeners were comparable to those of normal listeners, as long as the sensation levels were equivalent (Gordon-Salant and Fitzgibbons 1999; Moore and Glasberg 1988; Shailer and Moore 1983). However, other studies have shown that hearing-impaired listeners displayed elevated MGTs at high stimulus levels, and that their MGTs were more strongly influenced by stimulus level as compared to normal hearing listeners (Florentine and Buus 1984). Nelson and Thomas (1997) found that, at subjectively comfortable stimulus levels, listeners with mild to moderate hearing losses had elevated MGTs when compared to normal listeners, but when the carrier level was increased to subjectively loud levels, MGT was similar for both groups. Thus, the degree to which sensorineural hearing loss (SNHL) adversely affects temporal resolution remains in question.

Two of the most common animal models of agerelated SNHL, the CBA and C57BL/6 (C57) strains 
of laboratory mice, display markedly different time courses of SNHL. The hearing of the CBA mouse remains relatively stable throughout its lifespan; in the third year, there is a mild threshold shift of 20 to $30 \mathrm{~dB}$ throughout the audiometric range (Spongr et al. 1997; Willott et al. 1991). In contrast, C57 hearing begins to decline at very high frequencies as early as 2-3 months of age. By 6 months, they exhibit severe high frequency SNHL, and between 6 and 10 months, their hearing loss is in the range of 40 to $60 \mathrm{~dB}$ at high frequencies.

SNHL has been implicated to induce an alteration in the balance between excitatory and inhibitory influences on IC neurons (Barsz et al. 2007), which is likely related to changes in receptor activity after loss of peripheral input (Suneja et al. 1998). Along with extensive reorganization of the tonotopic map of the IC (Willott 1986, Irvine et al. 2003, Wang et al. 1996), Barsz et al. (2007) reported that IC units from hearing-impaired mice displayed broader frequency receptive fields. These data suggest that the inhibitory sidebands have been constricted, although a loss of excitation within the receptive field because of a loss of input from the periphery has also been implicated (Irvine et al. 2003). However, the driven activity in response to tones suggests that on-CF activity is also affected (Wang et al. 1996). Changes in the balance of excitation and inhibition, via blocking GABAergic circuits, have been shown to also alter the temporal response pattern of neurons (Le Beau et al. 1996, Vater et al. 1992). Finally, Caspary et al. (2002) have shown that the iontophoretic application of the $\mathrm{GABA}_{\mathrm{A}}$ receptor antagonist bicuculline can alter the response of IC neurons to sinusoidally amplitude modulated CF tones.

The major goal of this study was to differentiate neural deficits in gap detection because of aging from deficits attributed to peripheral hearing loss. In young normal hearing mice, MGTs measured in the inferior colliculus (IC) are on the order of $2 \mathrm{~ms}$ (Walton et al. 1997), comparable to behaviorally measured MGTs in rodents (Zhang et al. 1990; Allen et al. 2003) and humans (Forrest and Green 1987). MGTs shift to longer gap widths in old CBA mice with very mild SNHL (Walton et al. 1998), but because their SNHL occurs in old age, it is not clear whether age or SNHL loss was responsible. This study was initiated to test the hypothesis that mild to moderate SNHL could explain the deficits in temporal processing, as observed in the MGTs of old CBA mice. One can argue that middle-aged $\mathrm{C} 57$ mice have young brains but old ears because their SNHL occurs between 6 and 10 months. Because high frequency energy in the gap carrier contributes significantly to short minimal gap thresholds (Eddins et al. 1992), the high frequency SNHL exhibited by 6 - to10-month-old
C57 mice would be expected to adversely affect temporal acuity. Given the earlier results with old CBA mice, SNHL might be expected to alter MGT, unless such loss is primarily because of aging. Using similar measurement protocols as in our previous studies, we present results which illustrate that mild to moderate SNHL does not alter gap encoding at the single unit level in the auditory midbrain in young mice, leaving aging as the most probable cause of temporal sensitivity loss in old CBA mice.

\section{MATERIALS AND METHODS}

\section{Animals}

Fourteen normal-hearing (NH) (6-10 weeks of age) and 19 hearing-impaired (HI) (24-44 weeks of age) C57BL/6J mice were bred in the University of Rochester Vivarium; the original breeder pair was obtained from Jackson Laboratories. They were maintained in a quiet environment with ad lib food and water on a 12-h light/dark cycle. All procedures were approved by the University of Rochester's Committee on Animal Resources and in strict accordance with the National Institutes of Health Guide for the Care and Use of Animals.

\section{Surgical preparation}

Mice were anesthetized (Avertin, $200 \mathrm{mg} / \mathrm{kg}$ i.p.) supplemented with methoxyflurane (Metofane) inhalation as needed) and the cranium was exposed so that a small metal tube could be glued to the skull surface. A tungsten wire indifferent electrode was implanted in the skull just in contact with the dura mater. After a recovery period of at least 1 day, the mice were tranquilized with chlorprothixene (Taractan, 5$12 \mu \mathrm{g} / \mathrm{g}$ i.m.) which induces sedation by blocking 5-HT2, D1, D2, D3, H1, muscarinic and Alpha1 postsynaptic receptors (Goodman and Gilman 1996). Mice were briefly anesthetized with methoxyflurane (Metofane) inhalation and the IC exposed by making a small $(500 \mu \mathrm{m})$ craniotomy using stereotaxic coordinates. No recording took place until the anesthesia had worn off; thus, mice were in a tranquilized state during recording sessions. Mice were immobilized by bolting the metal tube to a stereotaxic frame (Newport-Klinger) located in a heated $\left(30-32^{\circ} \mathrm{C}\right)$ recording chamber (IAC). Recording sessions typically lasted between $8-10 \mathrm{~h}$; if a mouse showed signs of discomfort it was removed from the apparatus. Mice rested for at least 1 day between sessions, and completed no more than five sessions, all within 14 days of the initial surgery. In between recording sessions, the craniotomy was sealed with bone wax and/or gelfoam, and none of the mice experienced inflammation at the edges of the wound. 


\section{Stimuli and procedure}

Stimulus generation was controlled with a personal computer using a digital signal-processing interface (Tucker-Davis Technologies AP2). Noise was digitally generated, equalized to within $\pm 2 \mathrm{~dB}$ from 2 to 60 $\mathrm{kHz}$, amplified, and led to a high-frequency leaf tweeter (Panasonic THD 100) placed at $30^{\circ}$ azimuth contralateral to the recording site. Spike times (Tucker-Davis Technologies spike discriminator SD1 and event timer ET1) were acquired by the same computer. Search stimuli were 100-ms-long noise bursts with $5 \mathrm{~ms}$ cosine rise/fall times presented at $70 \mathrm{~dB}$ SPL and a rate of $4 / \mathrm{s}$.

Single units were isolated using conventional electrophysiological techniques. Action potentials (at least 2:1 signal-noise ratio) were recorded using glass micropipettes (A-M Systems) filled with either 3 M KCl (tip impedances of 8-12 M $\Omega$ ) or a $10 \%$ solution of horseradish peroxidase. The electrode tip was stereotactically positioned at the surface of the brain; a remote-controlled micropositioner (Newport-Klinger PMC100) was used to advance the electrode and indicate the depth of the tip in micrometers. Horseradish peroxidase microinjections were made on each mouse in the center of the recording sites. After $24 \mathrm{~h}$, the mice were perfused transcardially, the auditory tectum was sectioned, and the sections were examined to confirm that the injection was located in the IC (for more details see Walton et al. 1997). Units shown by histological analysis to be from outside the IC were excluded from the study. Audiovisual determination of noise threshold and best frequency (BF; the frequency with the lowest threshold) was performed by attenuating noise or pure tone bursts (Hewlett Packard 204D function generator) manually (Leader LAT-45). When acquisition time allowed, the unit's frequency response area was measured quantitatively by presenting $50-\mathrm{ms}$ tones ( $1 \mathrm{~ms}$ cosine rise/fall time) at the rate of $4 / \mathrm{s}$ within a three-octave range around the audiovisually determined BF. Each frequency was presented at 13 intensity levels spanning the expected sensitivity range for the unit. Rateintensity functions were obtained by presenting digitally generated tone or noise bursts (100 ms duration with $5 \mathrm{~ms}$ cosine rise/fall times) 25 times at the rate of $4 / \mathrm{s}$ and at intervals of $5 \mathrm{~dB}$ SPL from about $10 \mathrm{~dB}$ below threshold to $80 \mathrm{~dB}$ SPL.

Gap stimuli were noise bursts with cosine-shaped R/F times of $1 \mathrm{~ms}$ and durations of $150 \mathrm{~ms}$. Noise burst intensity was typically $65 \mathrm{~dB}$ SPL; when necessary noise bursts were adjusted to other intensities (1 unit each at 30, 40, and $55 \mathrm{~dB}$ SPL; 2 units at $60 \mathrm{~dB}$ SPL; 17 unit at 70 dB SPL; 18 units at $75 \mathrm{~dB}$ SPL; 8 units each at 80 and 85 $\mathrm{dB}$ SPL; 9 units at $90 \mathrm{~dB}$ SPL and 3 units at $100 \mathrm{~dB}$ SPL) to present stimuli near the unit's best noise intensity. These stimuli were presented 75 times at a rate of $2 / \mathrm{s}$. Silent gaps, with rise-fall times of $0.5 \mathrm{~ms}$, were embedded between the initial $100 \mathrm{~ms}$ (NB1) and the final $50 \mathrm{~ms}$ (NB2) of the noise burst. Gap stimuli were presented in a series that typically included the following gap durations: $0,2,3,6,12,24,48$, and $96 \mathrm{~ms}$. Additional gap durations were presented when necessary to maximize the accuracy of the MGT measurement.

\section{Data analysis}

Minimum thresholds (MTs) to tones and noise were obtained from the rate level functions for the respective signal and defined as the lowest intensity eliciting a noticeable change in the unit's spontaneous discharge rate. The number of spikes produced during the entire data acquisition period was counted and converted into spike rate. The rollover coefficient was calculated as the ratio between the greatest spike count and the spike count at the highest intensity of the rate-intensity function. We classified units with rollover coefficients of $<0.8$ as being nonmonotonic. The spontaneous rate was measured at least $10 \mathrm{~dB}$ below the noise threshold.

The temporal response pattern of each unit was classified based on visual inspection of the $0 \mathrm{~ms}$ gap PSTH according to the following criteria: sustained units had a steady level of activity throughout the duration of the stimulus with no phasic component; primary-like units had an initial peak response which gradually declined (similar to auditory nerve fiber responses). Phasic units produce a sharp peak at the beginning or end of the stimulus, followed by a sharp reduction to low or absent sustained activity. They were classified as on, off, or on/off depending on when the phasic discharge occurred relative to the stimulus. If there was sustained activity as well as phasic activity the unit was classified as on/sustained, sustained/off, or on/sustained/off. Build-up units had a very long latency followed by a slowly increasing spike count; the on/build-up unit included a phasic on response. Inhibitory units consistently displayed high spontaneous rates that were suppressed during the stimulus period. The unit classification is based on previously reported temporal response patterns in the CBA mouse (Willott et al. 1984; Walton et al. 1998, Fig. 3). Using the control (0 ms gap) stimulus, the mean and standard deviation (SD) of the unit's first spike latency were calculated with $1 \mu$ s precision using two measurement windows: a $25 \mathrm{~ms}$ window (for phasic units) or $50 \mathrm{~ms}$ window (for sustained units). Each window started at the onset of the response.

Neural correlates of MGT were quantified using the Wilcoxon signed-rank test and composite PSTH 
method previously described in detail (Barsz et al. 1998; see Fig. 1 in Barsz et al. 2000; Wilson and Walton 2002). MGT analysis was tailored individually for each unit, so that the analysis windows could account for differences in response latency across units. Phasic and sustained unit responses were analyzed using windows beginning at (1) the offset of NB1 response for sustained units and (2) the onset of the NB2 response for phasic units. The rationale for two different analysis windows is that gap encoding for sustained units typically occurs during the gap, whereas for onset units it occurs after the onset of NB2.

An example of the composite post-stimulus time histogram (PSTH) analysis for a sustained unit is shown on the left side of Figure 1. For clarity, the PSTHs for just three of the nine gap widths are shown ( 1,6 , and $24 \mathrm{~ms})$. The composite was constructed by simply adding the spike counts at identical bin locations from all of the individual histograms in a gap series. The bin containing the end of the response to NB1 was used as the start of the gap window $(\mathrm{GW})$, which had a variable duration equal to the gap duration being tested, and as denoted by the gray box. The response in the GW of each histogram was compared to the same time period in the control PSTH (lines denote comparison times). Response to the gap was defined as a significant difference between the response during the GW of the control and composite gap PSTHs periods.

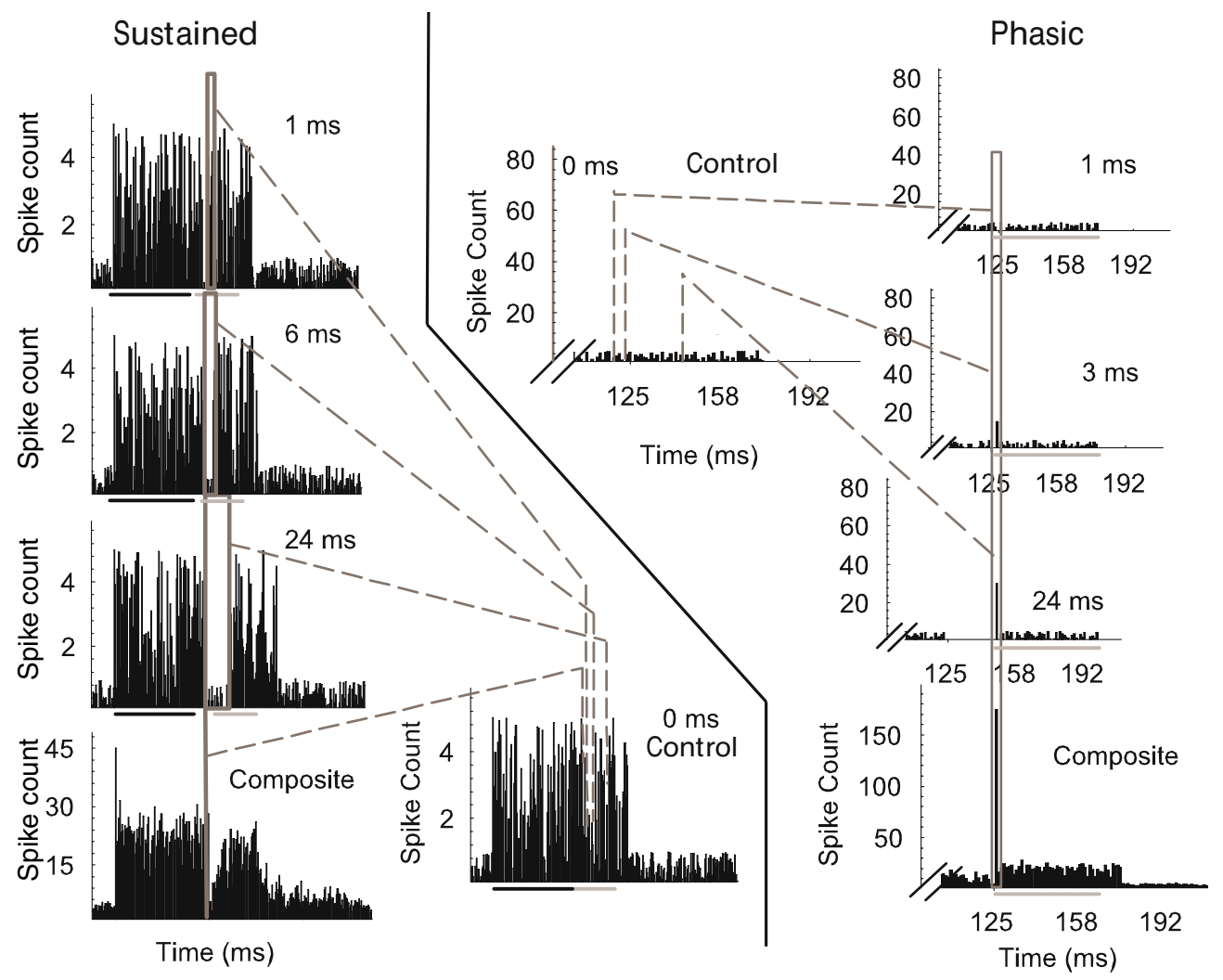

FIG. 1. An example of the composite post-stimulus time histogram (PSTH)analysisisshownforasustainedunit(left) and phasic unit (right). For clarity, the PSTHs for just three of the nine gap widths are shown. The composite histogram is shown at the bottom of each unit. For the sustained unit, it was constructed by adding the spike counts at identical bin locations from all of the individual histograms in a gap series. The bin containing the end of the response to NB1 was used as the start of the gap window (GW), which had a variable duration equal to the gap duration being tested, and as denoted by the gray box. The response in the GW of each histogram was compared to the same time period in the control PSTH (lines denote comparison times), provided that the GW ended before the control response was over. Longer GWs were truncated to the end of the control response to exclude non-driven activity in the control PST from entering into the comparison. The phasic unit's composite histogram was generated by shifting each gap PSTH "back in time" (to the left) by the gap duration and then summing all the spikes over the nine shifted gap PSTHs for gaps of 1 to $96 \mathrm{~ms}$. The onset and duration of the response to NB2 were visually determined from the composite histogram (gray box) and used to define the NB2 window (NW). The onset of the NW in each gap PSTH was adjusted by adding the gap width to the onset time established from the composite PSTH. For each gap width, spikes were counted in this window and this count was compared to the spike count within the same window in the control $(0 \mathrm{~ms})$ PSTH as shown by the dashed lines. A significant difference $(p<0.05)$ between the NW of the control and gap PSTHs periods indicated that the unit responded to the stimulus gap. The onset of this control window for each of the three PSTHs in the example is indicated by the dotted grey lines. Note that because the NW is adjusted by the gap width in each PSTH, the corresponding NW in the control PSTH is different for each gap width. The smallest gap producing a significant difference $(p<0.05)$ from the control was considered to be the gap threshold, providing that the next largest gap width also produced a significant difference. 
A composite histogram method was also used to analyze phasic units' response to stimulus gaps (Fig. 1, right). Here, the composite was generated by shifting each gap PSTH back in time (i.e., to the left) by the gap duration and then summing all the spikes over the nine shifted gap PSTHs (gaps of 1 to $96 \mathrm{~ms}$ ). The onset and duration of the response to NB2 were visually determined from the composite histogram (gray box) and used to define the NB2 window (NW). The onset of the NW in each gap PSTH was adjusted by adding the gap width to the onset time established from the composite PSTH. For each gap width, spikes were counted in this window and this count was compared to the spike count within the same window in the control (0 ms gap) PSTH. A significant difference between the NW of the control and gap PSTHs periods indicated that the unit responded to the stimulus gap. Note that because the NW onset is adjusted by the gap width in each PSTH, the corresponding NW in the control PSTH is different for each gap width.

For either unit type, the smallest gap producing a significant difference $(P<0.05)$ from the control was considered to be the gap threshold, providing that the next largest gap width also produced a significant difference. When no gap in the series was significantly different from the control, a minimal gap threshold (MGT) of $100 \mathrm{~ms}$ (greater than the largest gap width used in the experiment) was assigned so that the unit could be included in statistics and graphs.

NB2 recovery functions were determined for on and on/sustained units using a 25-ms NB2 count window. This window was shifted in time by an amount equal to the gap duration for each PSTH in the series, so that the number of spikes produced in response to the onset of NB2 could be determined. Spikes were counted in a 25-ms window beginning with the onset of the response to NB1. Normalized percent recovery for each gap duration was defined as the NB2 response divided by the NB1 response and multiplied by 100 .

\section{RESULTS}

\section{General characteristics of the sample}

A total of 480 units (241 from NH mice, 239 from HI mice) were encountered, with sufficient data being collected on 361 (189 from NH mice, 172 from HI mice) for inclusion in the analysis. Note that not all measurements were obtained for all units. The distribution of response types is shown in the top panel of Figure 2. A $\chi^{2}$ analysis comparing the frequency of off, primary-like, inhibitory, sustained, on, and on/sustained response types showed that HI mice had fewer inhibitory and on units but more primary-like units $\left(\chi^{2}(5)=18.77, p<.05\right)$. The other response types
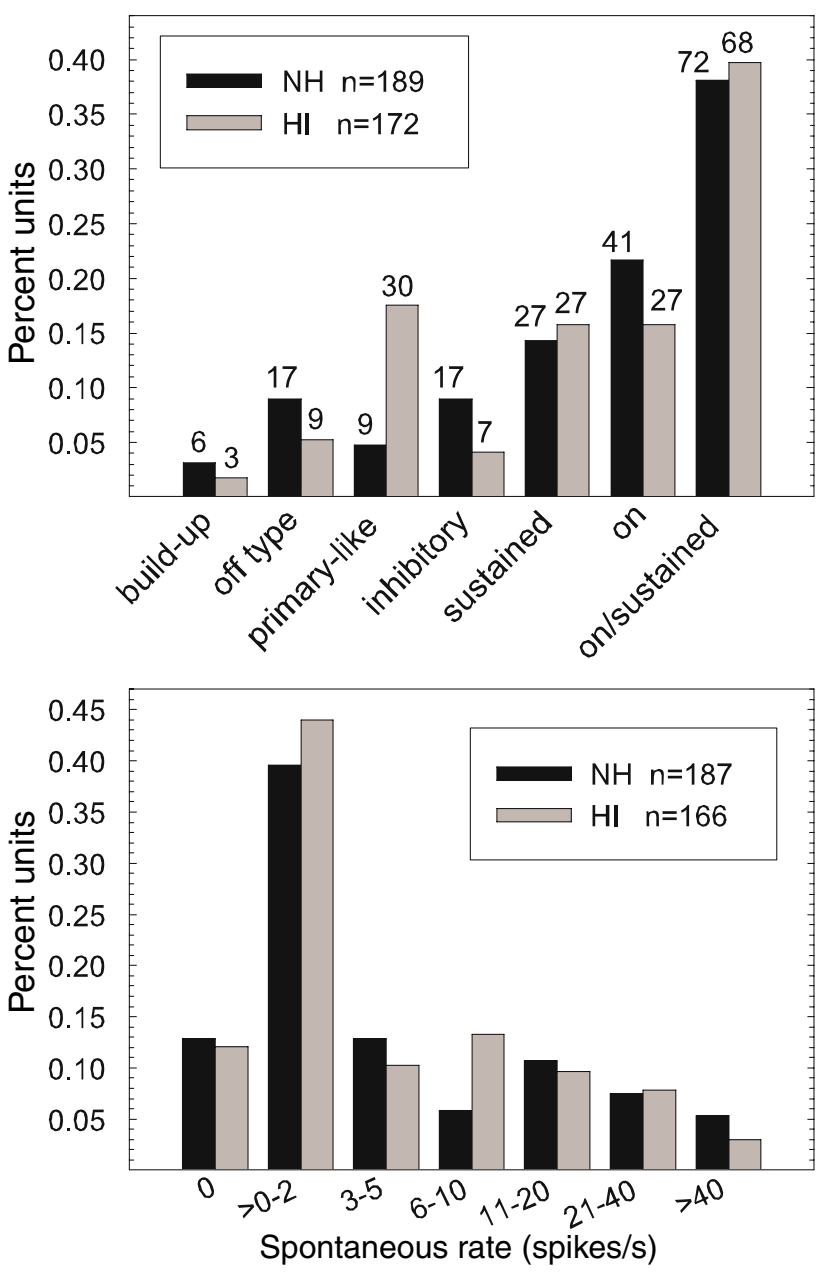

FIG. 2. Units with phasic (on or on/sustained) response patterns and low $(<3$ spikes/s) spontaneous rates were most prevalent in both $\mathrm{NH}$ and $\mathrm{HI}$ mice. The top panel shows the percentage distribution of response types, with the number of each type given above the bar. The bottom panel shows the distribution of spontaneous rates, among the units from $\mathrm{NH}$ and $\mathrm{HI}$ mice.

occurred too infrequently $(<5$ times) to allow for statistical comparison. Spontaneous rates were calculated for 187 units from NH mice and 166 units from HI mice, and the frequency distributions are displayed in the bottom panel of Figure 2. The mean spontaneous rate was 9.03 spikes/s $(\mathrm{SE}=1.37)$ in the $\mathrm{NH}$ sample and 7.00 spikes/s $(\mathrm{SE}=0.96)$ in the HI sample and this difference was not significant, $t(351)=1.18, p>0.05$. By far, the largest proportion of units in both groups had very low spontaneous discharge rates $(<0-2$ spikes $/ \mathrm{s})$.

$\mathrm{BF}$ is plotted against tone minimum thresholds (MT) for $189 \mathrm{NH}$ (open circles) and $166 \mathrm{HI}$ (filled circles) units in the top panel of Figure 3 . The mean $\mathrm{BF}$ was higher for units from $\mathrm{NH}$ mice $(M=16.54 \mathrm{kHz}$, $\mathrm{SE}=0.50)$ than $\mathrm{HI}$ mice $(M=10.07 \mathrm{kHz}, \mathrm{SE}=0.26)$, $t(348)=11.17, p<.05$. Tone thresholds were lower for units from $\mathrm{NH}$ mice $(M=22.91 \mathrm{~dB}$ SPL, SE=1.24) as compared to HI mice (33.72 dB SPL, SE=1.41), 

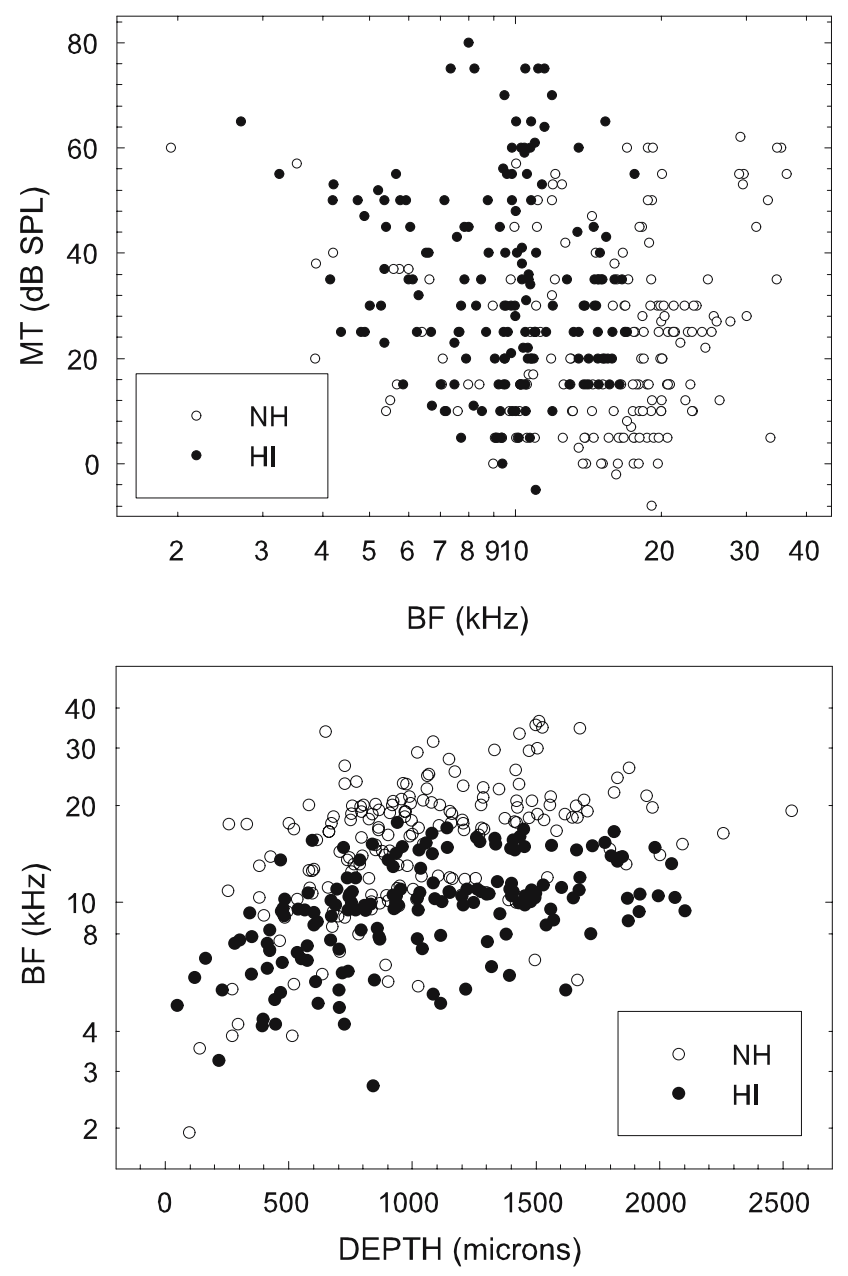

FIG. 3. The paucity of high BF units in $\mathrm{HI}$ mice is not because recordings were limited to dorsal recording locations within the IC. The top panel shows the unit BFs plotted against tone threshold for the units recorded from $\mathrm{NH}$ (open circles) and $\mathrm{HI}$ (filled circles) mice. It is clear that the $\mathrm{HI}$ sample is missing units with BFs above $18 \mathrm{kHz}$, and that more units from $\mathrm{NH}$ mice have thresholds under $5 \mathrm{~dB}$ SPL. In addition, there was more than a 2:1 difference, 78 vs $28 \%$, in the number of units with $\mathrm{BFs}<12 \mathrm{kHz}$ in $\mathrm{HI}$ mice as compared to $\mathrm{NH}$ mice. Data were missing from six $\mathrm{HI}$ units. The bottom panel shows the distribution of depths at which units were recorded from $\mathrm{NH}$ and $\mathrm{HI}$ mice. This distribution does not differ systematically between the $\mathrm{NH}$ and $\mathrm{HI}$ samples.

$t(347)=5.77, p<.05$. The mean noise threshold was also lower for units from NH mice (39.77 dB SPL, $\mathrm{SE}=1.20$ ) as compared to HI mice (data not shown) $(M=47.27$ dB SPL, SE $=1.23), t(358)=4.45, p<.05$. These data clearly demonstrate the expected highfrequency hearing loss in the 24- to 44-week-old C57 mice as compared to young controls.

We also compared the depths in which units were encountered from NH mice $(M=1,046.13 \mu \mathrm{m}$, $\mathrm{SE}=28.73, N=186)$ and HI mice $(M=1,006.81 \mu \mathrm{m}$, $\mathrm{SE}=30.97, N=166)$. The bottom panel of Figure 3 plots each unit's BF against the depth where it was encountered. There was no significant difference in the dorsal-ventral location where units were encoun- tered from $\mathrm{NH}$ and HI mice, $t(350)=0.23, p>0.05$. The fact that $\mathrm{BF}$ differed significantly between the $\mathrm{NH}$ and HI samples, while unit location along the dorsal-ventral tonotopic axis of the IC did not differ, suggests that units from HI mice recorded from the ventral IC had BFs which were lower than expected.

Mean first spike latencies are plotted against $\mathrm{BF}$ in Figure 4 for 157 units from NH mice (open circles) and 154 units from HI mice (filled circles). For phasic units, the expected inverse relationship between mean latency and $\mathrm{BF}$ was not found $(\mathrm{NH}$ $r=0.06$; HI $r=0.03$ ). This appears to be because of the large number of phasic units with short latencies at all BFs, as compared to long latencies. Six units from $\mathrm{HI}$ mice and 7 units from NH mice had latencies over $25 \mathrm{~ms}$. These units are denoted by arrows in Figure 4 (top panel), and were omitted from the correlational analysis of latency and $\mathrm{BF}$, which was significant for

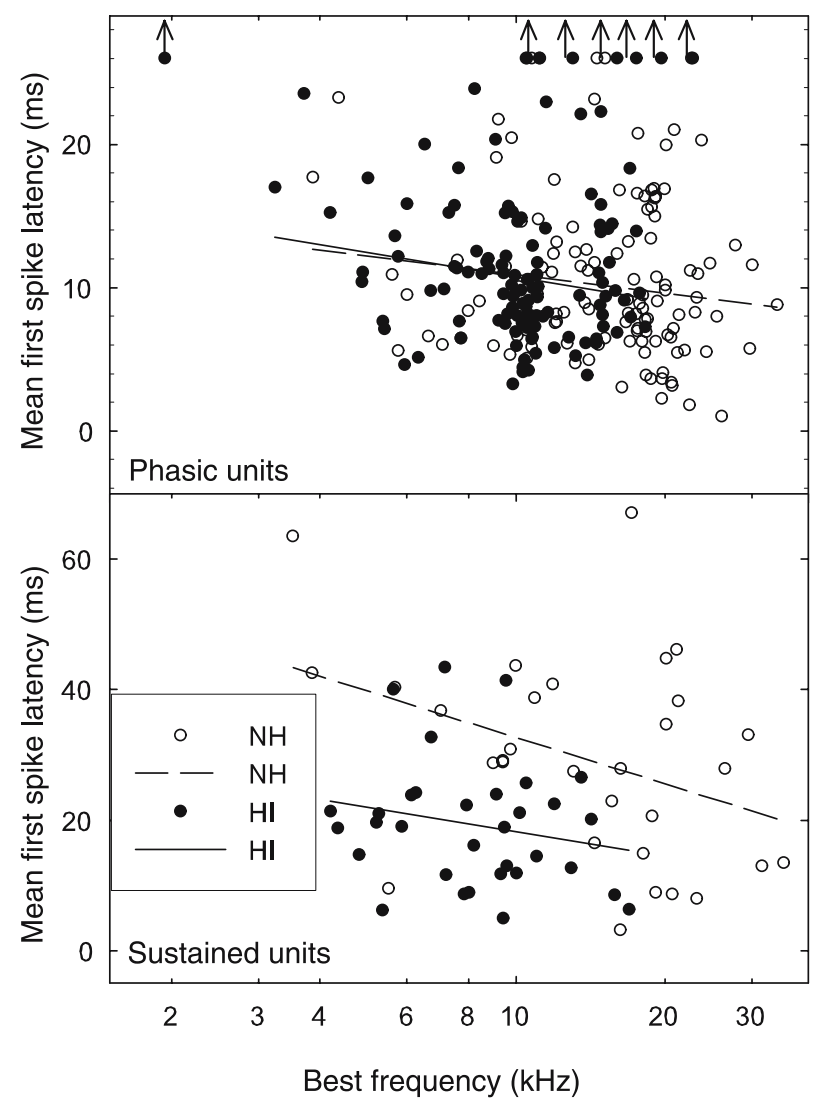

FIG. 4. Sustained units recorded from $\mathrm{NH}$ mice have longer latencies than sustained units recorded from $\mathrm{HI}$ mice. Mean first spike latency is plotted against BF for phasic units (top panel) and sustained units (bottom panel). Open circles indicate data recorded from $\mathrm{NH}$ mice; filled circles indicate data recorded from $\mathrm{HI}$ mice. A trend toward shorter latency with higher BF is seen except for 13 phasic units whose latencies were over $25 \mathrm{~ms}$ and were omitted from the regression analysis (six $\mathrm{HI}$ and seven $\mathrm{NH}$ units, all with BFs between $10-23 \mathrm{kHz}$, denoted by arrows). First spike latency data were available for 30 of the 38 sustained and primary-like units from $\mathrm{NH}$ mice, and 33 of the 57 sustained and primary-like units from $\mathrm{HI}$ mice. 
both NH $(r=-0.15)$ and HI $(r=-0.19$, both $p<.05)$ mice. The average first spike latency was almost identical for units recorded from $\mathrm{NH}(M=11.34 \mathrm{~ms}$, $\mathrm{SE}=0.64)$ and $\mathrm{HI}(M=11.77 \mathrm{~ms}, \mathrm{SE}=0.60)$ mice, $t(242)=0.50, p>0.05$. In contrast, sustained units (bottom panel) do show the expected BF by latency relationship (NH $r=-0.35$; HI $r=-0.23$ ). Moreover, the first spike latency for sustained units recorded from NH mice was significantly longer $(M=29.37 \mathrm{~ms}$, $\mathrm{SE}=2.82)$ as compared to units recorded from $\mathrm{HI}$ mice $(M=19.26 \mathrm{~ms}, \mathrm{SE}=1.71), t(62)=3.10, p<.05$.

Rollover coefficient was used to characterize the degree of monotonicity to increases in the intensity of $\mathrm{BF}$ tones and noise bursts. Using a criterion value of 0.8 , most units from both $\mathrm{NH}$ and $\mathrm{HI}$ mice exhibited monotonic rate-level functions for both tones $(\mathrm{NH}=59 \% ; \mathrm{HI}=65 \%)$ and noise stimuli $(\mathrm{NH}=61 \%$; $\mathrm{HI}=75 \%)$. The distribution of the rollover coefficients is displayed as box plots in Figure 5, with the data for BF tones shown on the left and noise on the right. The

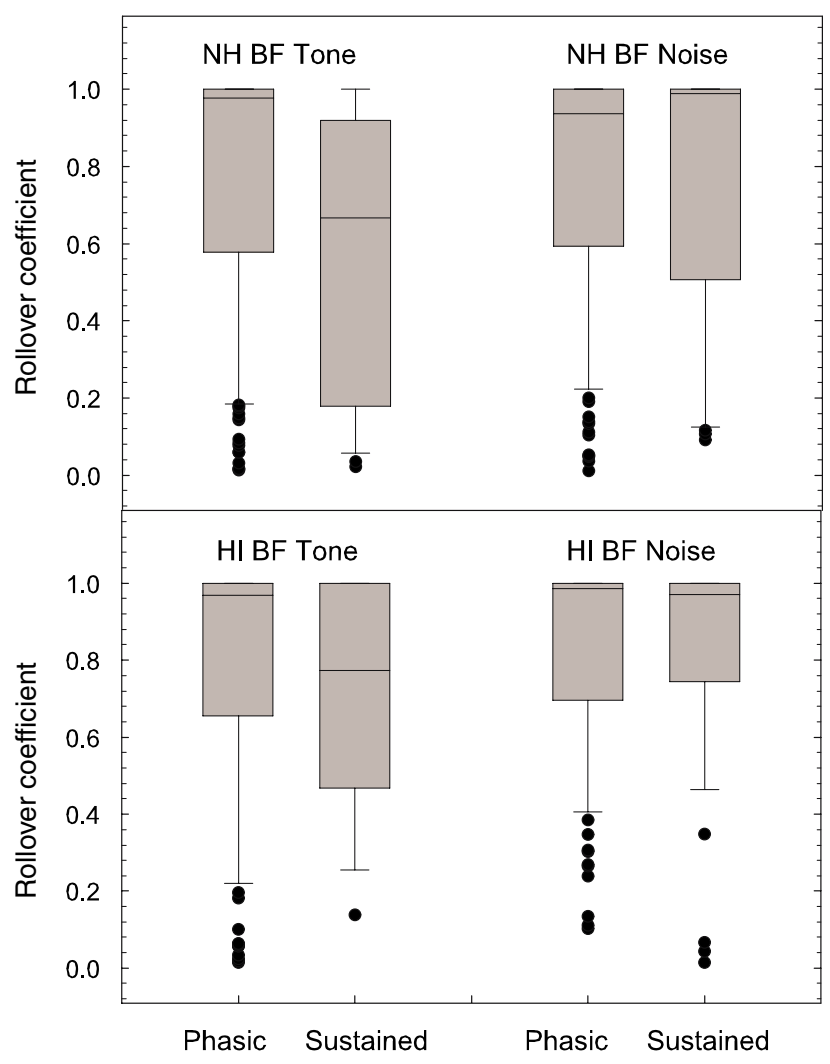

FIG. 5. The majority of phasic units from both $\mathrm{NH}$ and $\mathrm{HI}$ mice responded to stimuli monotonically with mean rollover coefficients near 1.0. However, sustained units recorded from both $\mathrm{NH}$ and $\mathrm{HI}$ mice responded nonmonotonically to tone bursts, with mean RCs below 0.8 , but monotonically to noise bursts. Distribution of rollover coefficients for phasic and sustained units from $\mathrm{NH}$ (top) and $\mathrm{HI}$ (bottom) mice for BF tones is shown on the left and for noise bursts on the right. Each box plot extends from the first to the third quartiles, with the horizontal line representing the median of the distribution. The whiskers indicate the 10th and 90th percentiles. The number of units included is shown in each box. means, standard errors and results of the $t$ tests are shown in Table 1. Mean coefficients are similar for NH and HI units and were between 0.72 and 0.84 , except that sustained units from $\mathrm{NH}$ mice tested with $\mathrm{BF}$ tones displayed greater rollover $(0.57)$.

\section{Neural gap thresholds}

Typical temporal response patterns to the gap stimuli are shown in Figure 6 from an NH mouse (left panel) and from an HI mouse (right panel). PSTHs in the first row show the response to the control (0 ms gap) stimulus, and the second row shows PSTHs at their MGTs of $6 \mathrm{~ms}$ for each unit. Note that the response at the MGT differs from the control (top row) in that an on response is elicited by NB2, denoted by the stimulus waveforms below each PSTH. The MGT response is characterized by a small response timelocked to NB2, but as gap duration increases the response increases until near full recovery occurred at $48 \mathrm{~ms}$ for each unit (bottom row). The major distinguishing feature between these two units was their noise threshold: $35 \mathrm{~dB}$ for the unit from the $\mathrm{NH}$ mouse and $45 \mathrm{~dB}$ for the unit from the HI mouse.

Median MGT was plotted as a function of age in the top panel of Figure 7. The $189 \mathrm{U}$ with MGTs recorded from $\mathrm{NH}$ mice are all included in the 5- to 10-week category, while the $167 \mathrm{HI}$ units are displayed in three age categories: 21-30 weeks (56 units), 31-40 weeks (89 units), and 41-50 weeks (22 units). The mean MGT was $9.12 \mathrm{~ms}(\mathrm{SE}=1.02)$ for units from $\mathrm{NH}$ mice, and $9.67 \mathrm{~ms}(\mathrm{SE}=1.40)$ for units from HI mice. These means were not significantly different, $t(354)=0.32, p>0.05$. Within the sample of units from HI mice, mean MGT was $6.18 \mathrm{~ms}$ for 2130 week olds, $11.86 \mathrm{~ms}$ for $31-40$ week olds, and 9.64 for 41-50 week olds. Thus, there was no systematic lengthening of MGT with the progression of agerelated high frequency SNHL. The bottom panel of Figure 7 plots the proportion of units with MGTs in each of four categories $(1-2,3-4,5-6$, and $>7 \mathrm{~ms})$. The occurrence of MGT values was different among units recorded from NH and HI mice, $\chi^{2}(4)=17.08$, $p<0.5$. More $1-2$ and $>7$ ms MGTs were found among units recorded from $\mathrm{NH}$ mice while more $3-4$ and 5-6 ms MGTs were found among units recorded from HI mice. Again, MGT did not change in a systematic fashion as the mice aged from 5 to 50 weeks.

We also examined whether MGT varied as a function of response type. Consistent with previous reports, MGT differed among units with different response patterns to noise, $F(5,320)=11.14, p<.05$, and this effect did not depend on the age of the mouse, $F(1,5)=0.52, p>0.05$. As seen in the top panel of Figure 8, units with on/sustained, on, primary-like, 
TABLE 1

\begin{tabular}{|c|c|c|c|c|}
\hline & & Phasic & Tonic & $t$ test \\
\hline \multirow[t]{2}{*}{ BF tones } & $\mathrm{NH}$ & 0.76 (se 0.03, n 151$)$ & 0.57 (se 0.07, n 25$)$ & $t(174)=2.87, p<0.05$ \\
\hline & $\mathrm{HI}$ & 0.78 (se $0.03, \mathrm{n} 126)$ & 0.72 (se $0.07, \mathrm{n} 16)$ & $t(140)=0.74, p>0.05$ \\
\hline \multirow[t]{2}{*}{ Noise bursts } & $\mathrm{NH}$ & 0.77 (se $0.03, \mathrm{n} 127)$ & 0.76 (se 0.06, n 38$)$ & $t(163)=0.21, p>0.05$ \\
\hline & $\mathrm{HI}$ & 0.83 (se $0.02, \mathrm{n} 103)$ & $0.84($ se $0.04, \mathrm{n} 44)$ & $t(145)=0.24, p>0.05$ \\
\hline
\end{tabular}
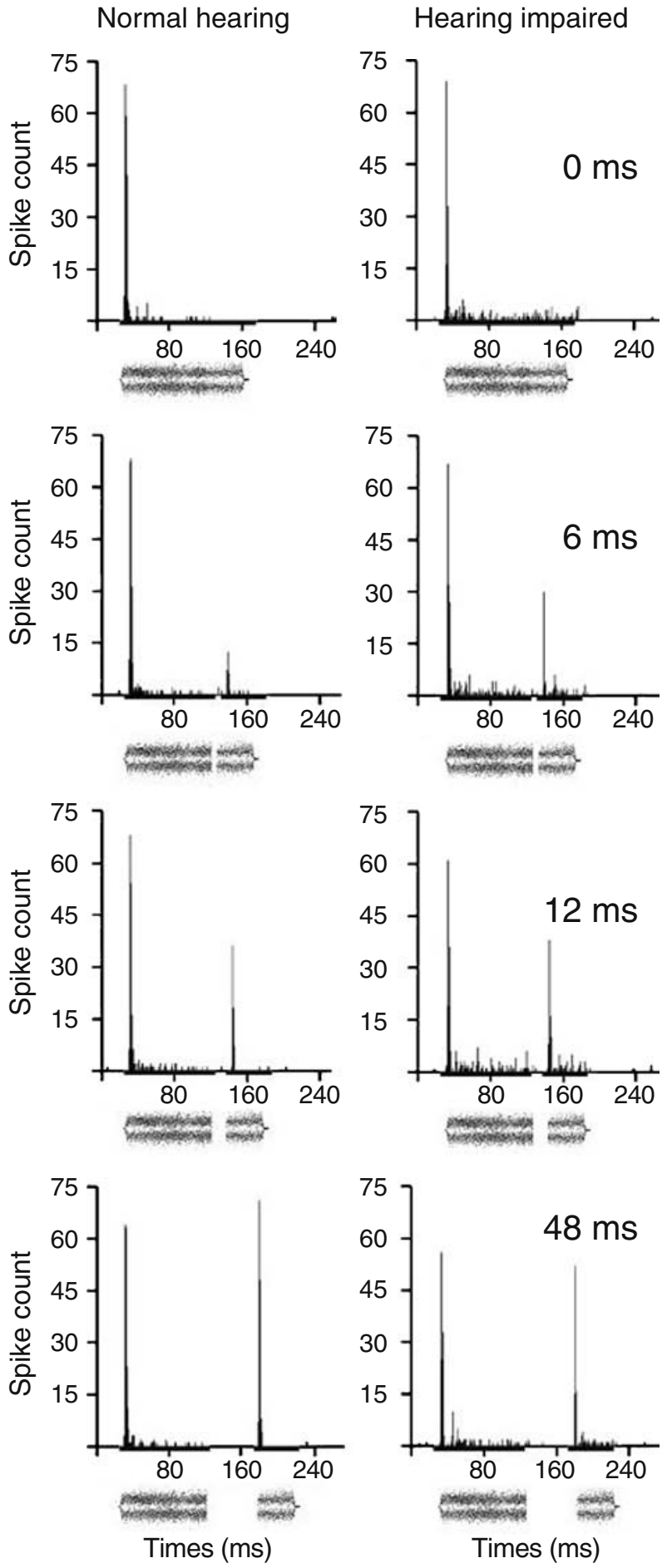

sustained, and build-up response patterns have mean MGTs under $10 \mathrm{~ms}$, while units with off and inhibitory response patterns have mean MGTs greater than 15 ms. The build-up units had to be excluded from the analysis of variance because of their low frequency (six recorded from $\mathrm{NH}$ mice, three recorded from $\mathrm{HI}$ mice). The bottom panel of Figure 8 shows the MGTs of units with different noise thresholds recorded from NH and HI mice. As evident from the figure, MGT was not affected by noise threshold, $F(6,338)=1.00, p>0.05$. Furthermore, MGT did not depend on the age of the mouse, $F(1,338)=0.56$, $\mathrm{p}>0.05$, or the interaction between age and noise threshold, $F(6,338)=0.23, p>0.05$. In fact, the gap stimuli were always presented at approximately the same SL (NH $M=25.9 \mathrm{~dB}$, HI $M=22.7 \mathrm{~dB})$.

\section{NB2 recovery functions}

The two top panels of Figure 9 show the NB2 recovery functions of 50 phasic units recorded from NH mice and 48 phasic units recorded from HI mice. To compare the rate of recovery from NB1 stimulation, best fit slopes were calculated using the spike counts between gap durations of 1 and 6,1 and 12, and 1 and $100 \mathrm{~ms}$. The mean slopes for all three time intervals were similar for $\mathrm{NH}$ and $\mathrm{HI}$ mice; from 1 to $6 \mathrm{~ms}, t(95)=0.63, p>0.05$, from 1 to $12 \mathrm{~ms}, t(96)=0.41$,

FIG. 6. Temporal responses patterns elicited by the gap stimuli were comparable for units recorded from $\mathrm{NH}$ and $\mathrm{HI}$ mice. The left column shows the responses of unit \#438 $(\mathrm{BF}=26.068 \mathrm{kHz}$, tone threshold $=27$ $\mathrm{dB}$ ) from an $\mathrm{NH} \mathrm{C57}$ mouse to noise bursts with (from top to bottom) 0 , 6,12 , and $48 \mathrm{~ms}$ gaps. The timing of the gap stimuli are indicated below each PSTH. Note that the NB2 response grows with the width of the gap. The right column show responses of unit \#319 $(\mathrm{BF}=13.920 \mathrm{kHz}$, tone threshold=30 dB) from an $\mathrm{HI} \mathrm{C57} \mathrm{mouse} \mathrm{to} \mathrm{the} \mathrm{same} \mathrm{stimuli.} \mathrm{Although}$ unit \#319 had a higher noise threshold (45 dB) than unit \#438 (noise threshold $35 \mathrm{~dB}$ ), the gap series was 25-30 dB above threshold for each unit, and the responses of the two units are almost indistinguishable. It is interesting to note that although the unit from the $\mathrm{HI}$ mouse had a lower $\mathrm{BF}$, the units were recorded at similar depths $(1,876 \mu \mathrm{m}$ for \#438 and 1,804 $\mu \mathrm{m}$ for \# 319) and had tone thresholds within $3 \mathrm{~dB}$ of each other. Both units responded to noise bursts with an on/sustained pattern (top row; responses to $150 \mathrm{~ms}$ noise bursts with $0 \mathrm{~ms}$ gaps), and both have low spontaneous rates (\#438(NH), 0.18 spikes/s; \#319(HI), 1.60 spikes/s). Their first spike latencies are similar $(\# 438(\mathrm{NH}): 1.00 \mathrm{~ms}, \mathrm{SD}=0.36$; $\# 319(\mathrm{HI}): 3.87 \mathrm{~ms}, \mathrm{SD}=3.31)$, as are their rollover coefficients $(\# 438(\mathrm{NH})$ : tone $=0.80$, noise $=1.13$; $\# 319(\mathrm{HI})$ : tone $=0.79$, noise $=1.16)$. 

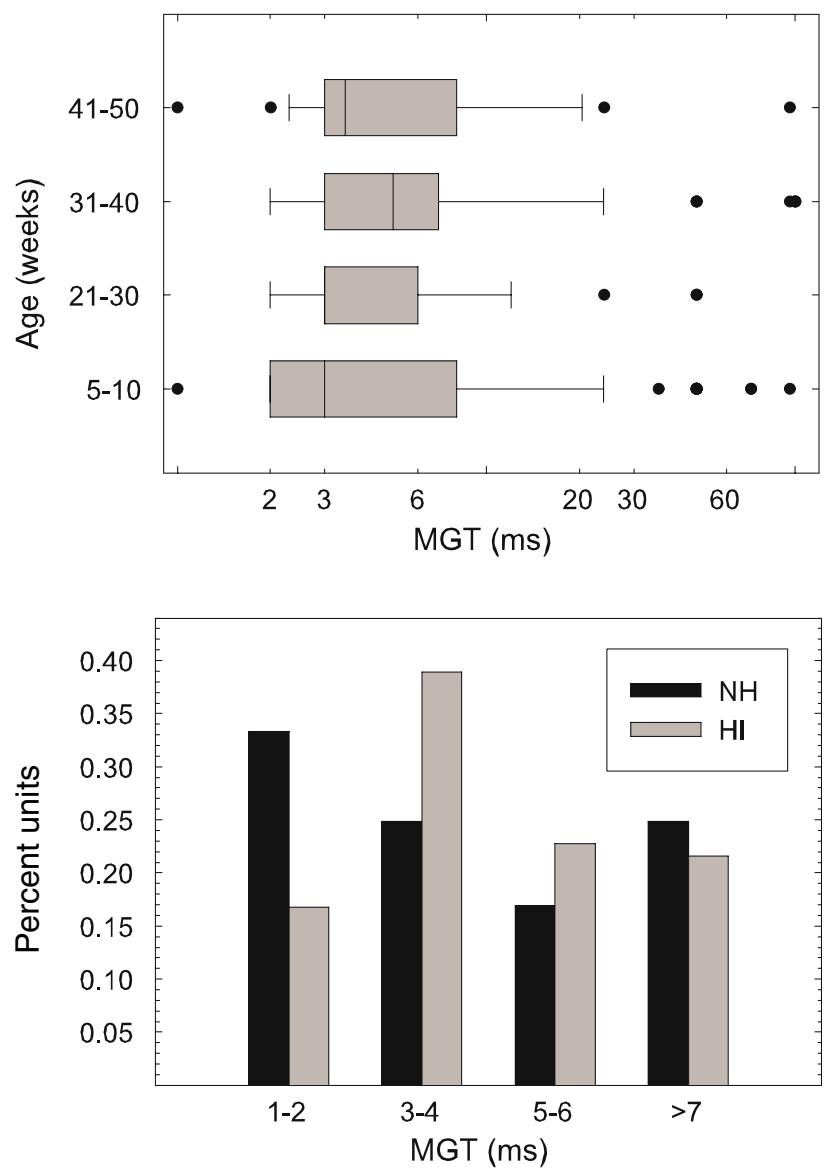

FIG. 7. No systematic age-related changes in MGT are apparent in the sample. In the top panel, the MGTs are displayed in box plots according to the age of the mouse from which each unit was recorded. Note that logarithmic coordinates are used to display MGTs; all outliers are included in the graph. Symbols are defined the same way as in Figure 5, with the data points indicating outliers. The median and 25th percentile MGT for the 21- to 30-week-old mice were both $3 \mathrm{~ms}$. The bottom panel shows the percentage of units recorded from $\mathrm{NH}$ and $\mathrm{HI}$ mice that had MGTs from 1-2, 3-4, 5-6, and $>7 \mathrm{~ms}$. The incidence of MGTs from 1-2 and $>7 \mathrm{~ms}$ was greater for $\mathrm{NH}$ mice, but the incidence of MGTs from 3-4 and 5-6 ms was greater for $\mathrm{HI}$ mice, so that no systematic age-related trend was found.

$p>0.05$, and from 1 to $100 \mathrm{~ms}, t(96)=0.87, p>0.05$. However, when we limited the comparison to only the rising portion of each gap function, the mean slopes of units from $\mathrm{HI}$ mice, $1.33(\mathrm{SE}=0.22)$, were significantly shallower than the slopes of units from NH mice, $2.42(\mathrm{SE}=0.50), t(99)=2.01, p<.05$. The box plots shown in the bottom panels display the median and inter-quartile percent recovery at 6 and $48 \mathrm{~ms}$ gaps. Values $<1.0$ indicate that the spike counts elicited by NB2 had not recovered to the count elicited by NB1. At $6 \mathrm{~ms}$, means were $35 \% \quad(\mathrm{SE}=4 \%)$ for $\mathrm{NH}$ mice compared to $47 \%$ ( $\mathrm{SE}=6 \%$ ) for $\mathrm{HI}$ mice. In both groups, recovery increased markedly at 48 $\mathrm{ms}$, to $75 \%(\mathrm{SE}=4 \%)$ for $\mathrm{NH}$ mice and $88 \%(\mathrm{SE}=6 \%)$ for HI mice. The change in percent recovery from 6 $\mathrm{ms}$ gap to $48 \mathrm{~ms}$ gap was statistically significant for
NH mice, $t(42)=7.93, p<.05$, and for HI mice, $t(48)=10.09, p<.05$. At $48 \mathrm{~ms}$ the majority of the units recorded from both $\mathrm{NH}$ and HI C57 mice had recovered to at least $75 \%$ of the NB1 response.

\section{DISCUSSION}

The principal finding of this study was that progressive SNHL had little influence on temporal processing in the
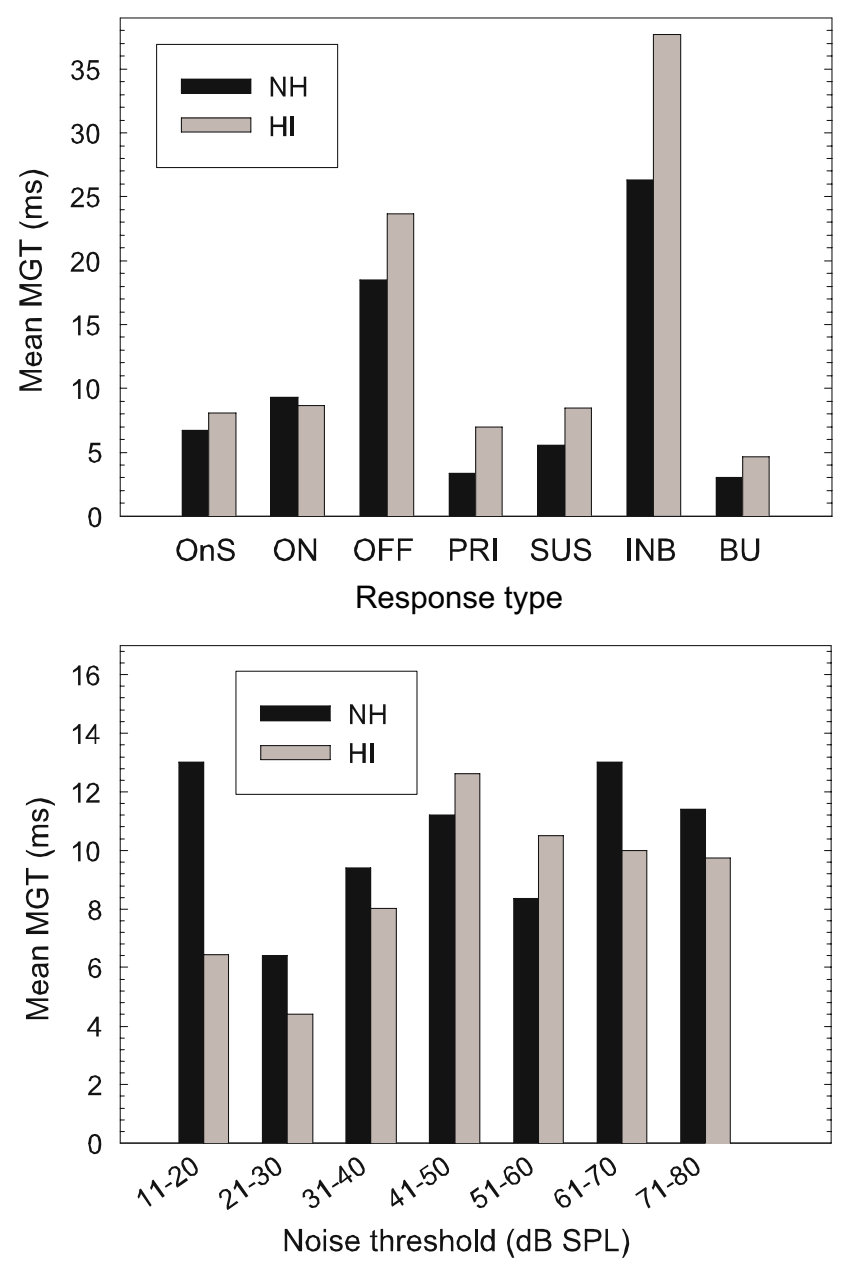

FIG. 8. MGTs varied with response type similarly in $\mathrm{NH}$ and $\mathrm{HI} I \mathrm{IC}$ units, and MGT did not vary with noise threshold. Mean MGT of units with the different response patterns to noise $(\mathrm{OnS}=$ on/sustained, $\mathrm{PRI}=$ primary-like, SUS = sustained, $\mathrm{INB}=$ inhibitory, $\mathrm{BU}=$ build-up) recorded from $\mathrm{NH}$ and $\mathrm{HI}$ mice are displayed in the top panel. The shortest MGTs are measured in OnS, ON, PRI, SUS, and BU units, and this did not depend on whether the unit was recorded from an $\mathrm{NH}$ or $\mathrm{HI}$ mouse. The bottom panel shows mean MGT of units with different noise thresholds; no systematic differences are apparent. The noise threshold categories of $0-10$ and $81-90 \mathrm{~dB}$ were excluded from the figure and also from the ANOVA because of the small number of units in them: There was one unit with a noise threshold of $0 \mathrm{~dB}$ and an MGT of $12 \mathrm{~ms}$, one with a noise threshold of $83 \mathrm{~dB}$ and an MGT of $2 \mathrm{~ms}$, and one with a noise threshold of $85 \mathrm{~dB}$ and an MGT of $24 \mathrm{~ms}$. These three units were all recorded from $\mathrm{HI}$ mice, and their data are consistent with the conclusion that MGT was unrelated to noise threshold. 

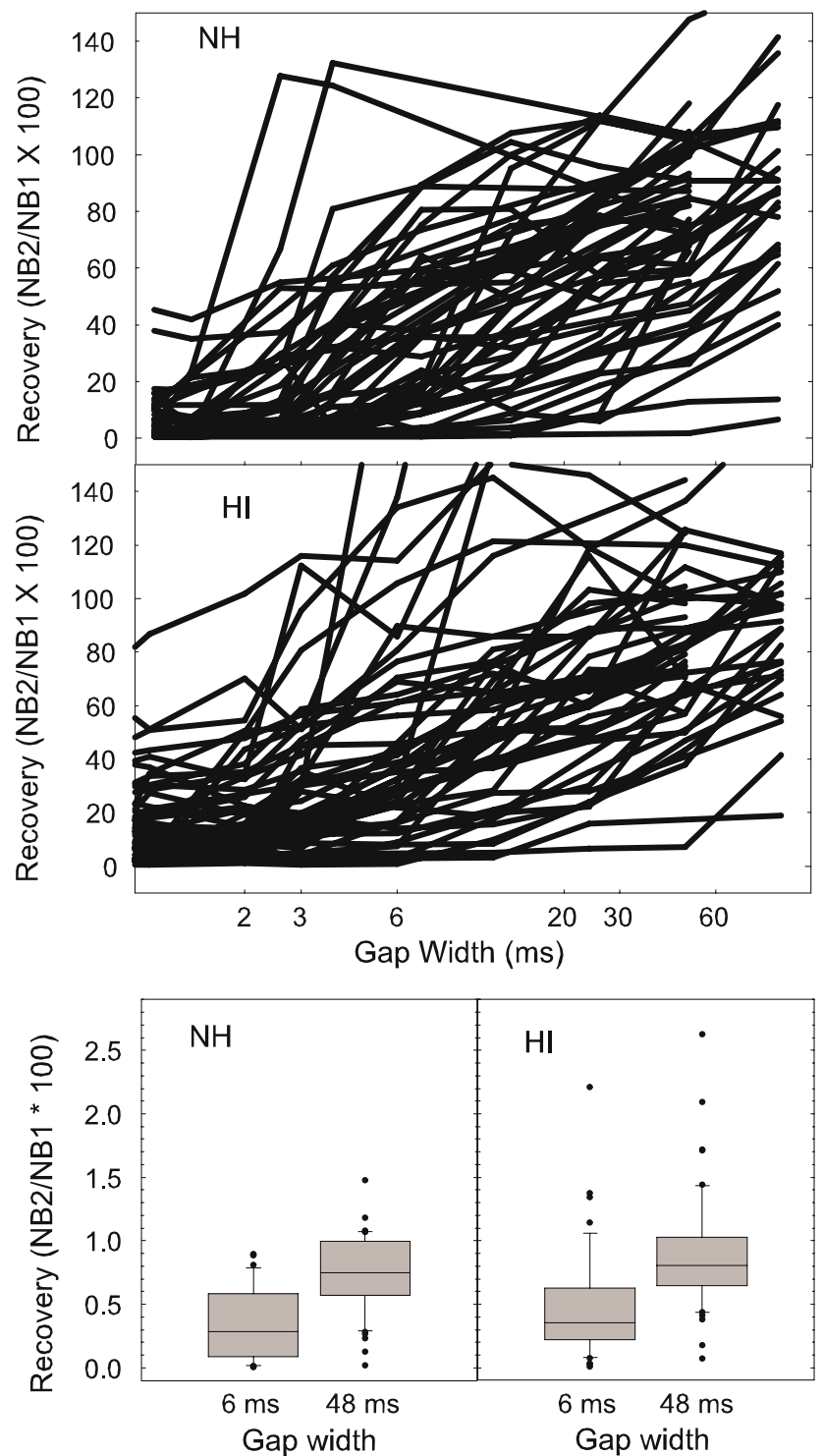

FIG. 9. There is no apparent difference between the $\mathrm{NH}$ and $\mathrm{HI}$ gap functions. Gap recovery functions for $\mathrm{NH}$ and $\mathrm{HI}$ mice, showing the strength of the response to NB2 relative to the response to NB1 as gap duration increases. The two top panels show the normalized NB2 response of phasic units from $\mathrm{NH}$ and $\mathrm{HI}$ C57 mice. Percent recovery at $6 \mathrm{~ms}$ gap widths and $48 \mathrm{~ms}$ gap widths are displayed in box plots in the bottom panels. Note that the $6 \mathrm{~ms}$ gap was not presented to every unit ( $\mathrm{NH}: n=43 ; \mathrm{HI}: n=47)$.

inferior colliculus as measured with the gap detection paradigm, an important finding in the context of the reported decline in temporal acuity in old CBA mice using the same measures (Walton et al. 1998). Although middle-aged C57 mice exhibit moderate to severe high frequency SNHL, the ability of single units to code silent gaps embedded in noise carriers was found to be similar to units recorded in young normal hearing C57 mice. Thus, SNHL, in and of itself, independently of aging is not responsible for temporal processing deficits, as measured by gap detection paradigm in IC neurons from old CBA mice. Auditory function of the C57 mouse was first characterized by Willott, who used it as a mouse model of progressive age-related hearing loss (Johnson et al. 1997; Willott 1986; Willott et al. 1984; Willott et al. 1988, 1991). In a series of reports they characterized the time course of SNHL as beginning at about 2 months of age, with significant spiral ganglion degeneration observed at 12 months of age. Spongr et al. (1997) reported that during the 8-month period during which we recorded from the IC, $90 \%$ of outer hair cells were absent in the base, as compared to just over $10 \%$ in the middle and apical cochlear regions. In contrast, $60 \%$ of basal inner hair cells were absent as compared to under $20 \%$ in the middle and apical cochlea (White et al. 2000). In the face of this genetically programmed spiral ganglion loss and concomitant SNHL, one might expect to observe significant changes in central auditory processing.

\section{Effects on basic response properties}

The proportion of different temporal response patterns to noise stimuli of units recorded from $\mathrm{NH}$ mice was comparable to the distribution reported for responses to tones by Willott and McFadden (McFadden and Willott 1994; Willott et al. 1988) with on-sustained units being the most prevalent, followed by onset type units. When units with poor driven responses were excluded, (Willott et al. 1988 ) reported a significant decrease in the proportion of units from HI mice that exhibited sustained type discharge patterns, but it is possible that phasic units appeared more "sluggish" and thus were preferentially excluded, biasing the sample. In this study, we found that the basic response properties were changed in that the hearing impaired C57 IC yielded fewer inhibitory and on neurons and more primary-like neurons. This result suggests that inhibition in the HI IC has been weakened.

Willott et al. (1997) found a significant decline in the number of glycine-immunoreactive neurons in the cochlear nucleus of 18 months, but not 12 months, C57 mice. Furthermore, it is likely that the balance of inhibition and excitation changes in the IC after hearing loss (Rajan 2001). Therefore, although the levels of inhibitory neurotransmitters before and after SNHL have not been directly compared, the chain of evidence strongly suggests that they are reduced. Additionally, calbindin and calretinin have been shown to be altered (Zettel et al. 1997; Zettel et al. 2001). Because these proteins regulate intracellular calcium, and therefore neural excitation, these changes could also alter the excitation/inhibition balance.

In the present study, spontaneous rates of IC units were generally low $(<3$ spikes/s), and not significantly different between NH and HI units. Willott et al. (1988) reported that the proportion of units exhibiting obvious spontaneous activity ( $>1$ spikes/s) was lower in NH C57 
mice. There were a number of procedural differences between the studies that make it difficult to directly compare the results, and the effect of SNHL on spontaneous rate deserves more systematic investigation. However, it is of note that iontophorectic application of bicuculline has little effect on the spontaneous rate of IC neurons (Le Beau et al. 1996).

We found that $59 \%$ of units recorded from $\mathrm{NH}$ mice and $65 \%$ recorded from HI mice were monotonic. This compares well with Willott et al. (1988), who used 0.75 or greater to signify monotonic functions, and found $52 \%$ of tone RIFs to be monotonic in $\mathrm{NH} \mathrm{C} 57$ mice vs $66 \%$ in the HI mice. However, among sustained units, the average rollover coefficient in responses to tones was increased in the HI IC. This finding supports the inference that SNHL is associated with changes in the inhibition/ excitation balance, but only in the response of sustained units. Phasic units had higher mean rollover coefficients which did not change with SNHL. In other studies, units with phasic onset responses have been shown to have the shortest MGTS, comparable to behaviorally measured gap thresholds (Walton et al. 1997).

Minimum first spike latency provides a metric of temporal encoding to stimulus onset, but the available evidence suggests that alterations in inhibition, whether age-related (Palombi and Caspary 1996) or the result of iontophoretic manipulations (Fuzessery et al. 2003) have little effect on this measure. Indeed, we found no significant differences in minimum first spike latency between phasic units from $\mathrm{NH}$ and $\mathrm{HI}$ C57 mice. More specifically, there were no significant SNHL-related changes in the phasic units, but the latency decreased in the sustained units recorded from the HI mice. Perhaps, as with monotonicity, the balance of inhibition and excitation primarily influences units that do not mediate temporal acuity.

\section{Effects on minimum gap thresholds}

The question posed by this experiment, whether SNHL is related to loss of temporal sensitivity as measured by the MGT, is decidedly answered in the negative. Despite a hearing loss of $22 \mathrm{~dB}$ for tones and $40 \mathrm{~dB}$ for noise, the IC neuron MGTs of the HI C57 mice were not statistically different than the mean MGTs for the NH mice, and MGT was not affected by the noise MT in the older $\mathrm{C} 57$ mice. Using similar measures as the present study, IC units recorded from older CBA mice having a flat SNHL of 20-30 dB (tones) had a significantly greater proportion of units with long MGTs as compared to units recorded from young CBA mice (Walton et al. 1998). Finlayson (2002) measured post-stimulatory suppres- sion in the IC single units of old rats and found that recovery occurred with a mean time constant of 101 ms, compared to $71 \mathrm{~ms}$ mean time constant measured in young rats. Temporal processing deficits have also been reported in old gerbils using far-field recording of responses to gap stimuli (Boettcher et al. 1996). In contrast, Tomita et al. (2004) found that VOT and MGT were unrelated to SNHL. Together, these results support the conclusion that SNHL alone cannot explain alteration in temporal sensitivity.

\section{Summary}

In summary, the C57 mouse undergoes a rapid SNHL that is characteristic of many human forms of genetic and acquired hearing impairment. A major aim of this study was to measure the effects of hearing loss on IC gap encoding properties to determine whether SNHL could account for the decline in temporal sensitivity observed in IC units recorded from in old CBA mice. Walton et al. (1998) reported that, while almost half of the units recorded from the IC of 2- to 3.5-month-old CBA mice had MGTs of $1 \mathrm{~ms}$, only $20 \%$ of the units recorded from 24- to 28-month-old CBA mice (with no more than 30 dB HL at any frequency) had such a low MGT. Furthermore, the proportions of units with MGTs over $1 \mathrm{~ms}$ rose. In addition, the recovery functions of most units from the younger mice were at $100 \%$ for a 5-ms gap, while none of the units recorded from the older mice had recovered to $100 \%$ when the gap duration was $5 \mathrm{~ms}$, and many units had not recovered to $100 \%$ for a $30-\mathrm{ms}$ gap. In these respects, the gap data obtained from the HI C57 mice in the present study resemble those of the young CBA mice, and not those of the old CBA mice, even though their HL is much more severe. Thus, we conclude that the quantitative descriptions of neural correlates of gap detection, the gap threshold, and change in strength of response with increases in gap duration, are affected by age rather than SNHL. Suprathreshold temporal acuity comparable to young controls, in the face of severe high frequency peripheral loss, is suggestive of compensatory mechanisms. These mechanisms should be the focus of future studies. The major conclusion remains: temporal sensitivity, at least as it is reflected in minimum gap thresholds, is not impaired by hearing loss.

\section{ACKNOWLEDGEMENTS}

This research was supported by NIH/NIA grant PO1 AG09524 and by the Rochester International Center for Hearing and Speech. 


\section{REFERENCES}

Allen PD, Burkard RF, Ison JR, Walton JP. Impaired gap encoding in aged mouse inferior colliculus at moderate but not high stimulus levels. Hear. Res. 186:17-29, 2003.

Barsz K, Benson PK, WaLton JP. Gap encoding by inferior collicular neurons is altered by minimal changes in signal envelope. Hear. Res. 115:13-26, 1998.

Barsz K, WiLson WW, WaLton JP. Background noise differentially effects temporal coding by tonic units in the mouse inferior colliculus. Hear. Res. 150:149-160, 2000.

Barsz K, WILSON WW, WALTON JP. Reorganization of receptive fields following hearing loss in inferior colliculus neurons. Neuroscience 147:532-545, 2007.

Boettcher FA, Mills JH, Swerdloff JL, Holley BL. Auditory evoked potentials in aged gerbils: Responses elicited by noises separated by a silent gap. Hear. Res. 48:167-178, 1996.

Caspary DM, Palombi PS, Hughes LF. GABAergic inputs shape responses to amplitude modulated stimuli in the inferior colliculus. Hear. Res. 168:163-173, 2002.

Eddins DA, Hall JW, 3Rd, Grose JH. The detection of temporal gaps as a function of frequency region and absolute noise bandwidth. J. Acoust. Soc. Am. 91:1069-1077, 1992.

FinlaYson PG. Paired-tone stimuli reveal reductions and alterations in temporal processing in inferior colliculus neurons of aged animals. J. Assoc. Res. Otolaryngol. 3:321-331, 2002.

Florentine M, Buus S. Temporal gap detection in sensorineural and simulated hearing impairments. J. Speech Hear. Res. 27:449-455, 1984.

Forrest TG, Green DM. Detection of partially filled gaps in noise and the temporal modulation transfer function. J. Acoust. Soc. Am. 82:1933-1943, 1987.

Fuzessery ZM, Wenstrup JJ, Hall JC, Leroy S. Inhibition has little effect on response latencies in the inferior colliculus. J. Assoc Res. Otolaryngol. 4:60-73, 2003.

Goodman LS, Gilman A. Goodman \& Gilman's the Pharmacological Basis of Therapeutics. New York, NY, McGraw-Hill, 1996.

Gordon-Salant S, Fitzgibbons PJ. Profile of auditory temporal processing in older listeners. J. Speech Lang. Hear. Res. 42:300-311, 1999.

Irvine DR, Rajan R, Smith S. Effects of restricted cochlear lesions in adult cats on the frequency organization of the inferior colliculus. J. Comp. Neurol. 467:354-374, 2003.

Ison JR, Allen P. A diminished rate of "physiological decay" at noise offset contributes to age-related changes in temporal acuity in the CBA mouse model of presbycusis. J. Acoust. Soc. Am. 114:522-528, 2003.

Johnson KR, Erway LC, CoOK SA, Willott JF, Zheng QY. A major gene affecting age-related hearing loss in $\mathrm{C} 57 \mathrm{Bl} / 6 \mathrm{j}$ mice. Hear Res. 114(1-2):83-92, 1997.

Le Beau Fe, Rees A, Malmierca MS. Contribution of gaba- and glycine-mediated inhibition to the monaural temporal response properties of neurons in the inferior colliculus. J. Neurophysiol. 75:902-919, 1996.

McFAdDEN SL, WiLlott JF. Responses of inferior colliculus neurons in $\mathrm{C} 57 \mathrm{Bl} / 6 \mathrm{~J}$ mice with and without sensorineural hearing loss: Effects of changing the azimuthal location of an unmasked pure-tone stimulus. Hear. Res. 78:115-131, 1994.

Moore BC, Glasberg BR. Gap detection with sinusoids and noise in normal, impaired, and electrically stimulated ears. J. Acoust. Soc. Am. 83:1093-1101, 1988.

Nelson PB, Thomas SD. Gap detection as a function of stimulus loudness for listeners with and without hearing loss. J. Speech Lang. Hear. Res. 32:1387-1394, 1997.
Palombi PS, Caspary DM. Physiology of the aged Fischer 344 rat inferior colliculus: Responses to contralateral monaural stimuli. J. Neurophysiol. 76:3114-3125, 1996.

Rajan R. Plasticity of excitation and inhibition in the receptive field of primary auditory cortical neurons after limited receptor organ damage. Cereb. Cortex. 11:171-182, 2001.

Shailer MJ, Moore BC. Gap detection as a function of frequency, bandwidth, and level. J. Acoust. Soc. Am. 74:467-473, 1983.

Spongr VP, Flood DG, Frisina RD, Salvi RJ. Quantitative measures of hair cell loss in CBA and $\mathrm{C} 57 \mathrm{Bl} / 6$ mice throughout their life spans. J. Acoust. Soc. Am. 101:3546-3553, 1997.

Suneja SK, Potashner SJ, Benson CG. Plastic changes in glycine and GABA release and uptake in adult brain stem auditory nuclei after unilateral middle ear ossicle removal and cochlear ablation. Exp. Neurol. 151:273-288, 1998.

Tomita M, Norena AJ, Eggermont JJ. Effects of an acute acoustic trauma on the representation of a voice onset time continuum in cat primary auditory cortex. Hear. Res. 193:39-50, 2004.

Vater M, Habbicht H, Kossl M, Grothe B. The functional role of GABA and glycine in monaural and binaural processing in the inferior colliculus of horseshoe bats. J. Comp. Physiol. [A] 171:541-553, 1992.

WALton JP, Frisina RD, Ison JR, O’NeILl WE. Neural correlates of behavioral gap detection in the inferior colliculus of the young CBA mouse. J. Comp. Physiol. [A]. 181:161-176, 1997.

Walton JP, Frisina RD, O’Neill WE. Age-related alteration in processing of temporal sound features in the auditory midbrain of the CBA mouse. J. Neurosci. 18:2764-2776, 1998.

Wang J, Salvi RJ, Powers N. Plasticity of response properties of inferior colliculus neurons following acute cochlear damage. J. Neurophysiol. 75:171-183, 1996.

White JA, Burgess BJ, Hall RD, Nadol JB. Pattern of degeneration of the spiral ganglion cell and its processes in the $\mathrm{C} 57 \mathrm{Bl} / 6 \mathrm{j}$ mouse. Hear. Res. 141:12-18, 2000.

WiLLotT JF. Effects of aging, hearing loss, and anatomical location on thresholds of inferior colliculus neurons in $\mathrm{C} 57 \mathrm{Bl} / 6$ and CBA mice. J. Neurophysiol. 56:391-408, 1986.

Willott JF, Kulig J, Satterfield T. The acoustic startle response in $\mathrm{dba} / 2$ and $\mathrm{C} 57 \mathrm{Bl} / 6$ mice: Relationship to auditory neuronal response properties and hearing impairment. Hear. Res. 16:161-167, 1984.

Willott JF, Parham K, Hunter KP. Response properties of inferior colliculus neurons in middle-aged $\mathrm{C} 57 \mathrm{Bl} / 6 \mathrm{j}$ mice with presbycusis. Hear. Res. 37:15-27, 1988.

Willott JF, Parham K, Hunter KP. Comparison of the auditory sensitivity of neurons in the cochlear nucleus and inferior colliculus of young and aging $\mathrm{C} 57 \mathrm{Bl} / 6 \mathrm{j}$ and $\mathrm{CBA} / \mathrm{j}$ mice. Hear. Res. 53:78-94, 1991.

Willott JF, Milbrandt JC, Bross LS, Caspary DM. Glycine immunoreactivity and receptor binding in the cochlear nucleus of $\mathrm{C} 57 \mathrm{Bl} / 6 \mathrm{j}$ and $\mathrm{CBA} / \mathrm{CaJ}$ mice: Effects of cochlear impairment and aging. J. Comp. Neurol. 385:405-414, 1997.

WiLson WW, Walton JP. Background noise improves gap detection in tonically inhibited inferior colliculus neurons. J Neurophysiol. 87:240-249, 2002

Zettel ML, Frisina RD, Haider SE, O’Neill WE. Age-related changes in calbindin $\mathrm{d}-28 \mathrm{k}$ and calretinin immunoreactivity in the inferior colliculus of $\mathrm{CBA} / \mathrm{CaJ}$ and $\mathrm{C} 57 \mathrm{Bl} / 6$ mice. J. Comp. Neurol. 386:92-110, 1997.

Zettel ML, O’Neill We, Trang TT, Frisina RD. Early bilateral deafening prevents calretinin up-regulation in the dorsal cortex of the inferior colliculus of aged $\mathrm{CBA} / \mathrm{CaJ}$ mice. Hear. Res. 158:131-138, 2001.

Zhang W, SALVI RJ, SAUNDERS SS. Neural correlates of gap detection in auditory nerve fibers of the chinchilla. Hear. Res. 46:181-200, 1990. 